\title{
Morphology of the Kosi megafan channels
}

\author{
K. Gaurav ${ }^{1}$, F. Métivier ${ }^{1}$, O. Devauchelle ${ }^{1}$, R. Sinha ${ }^{2}$, H. Chauvet ${ }^{1}$, M. Houssais ${ }^{3}$, and H. Bouquerel ${ }^{1}$ \\ ${ }^{1}$ Institute de Physique du Globe de Paris, 1 Rue Jussieu, 75005 Paris CEDEX 05, France \\ ${ }^{2}$ Department of Earth Sciences, Indian Institute of Technology, Kanpur, 208016 UP, India \\ ${ }^{3}$ Department of Earth and Environmental Science, University of Pennsylvania, Philadelphia, PA 19104, USA \\ Correspondence to: K. Gaurav (gaurav@ipgp.fr)
}

Received: 16 September 2014 - Published in Earth Surf. Dynam. Discuss.: 1 October 2014

Revised: 31 March 2015 - Accepted: 18 May 2015 - Published: 21 July 2015

\begin{abstract}
We report on a new set of measurements on the morphology of braided and meandering threads of the Kosi megafan, North Bihar, India. All threads develop on a uniform sandy sediment and under a similar climate. The data set is composed of the width, depth, water discharge and grain size of 51 threads. Downstream slopes and sinuosity are also available. Using this data set, we show that braided and meandering threads share common hydraulic geometries. We then use the threshold theory to explain why the aspect ratio of threads is almost naturally detrended, and rescale the data according to this theory. As expected, the rescaled dimensions of braided and meandering threads are weakly correlated to water discharge. We propose that the large dispersion observed, which is common to meandering and braided threads, is the signature of sediment transport, vegetation or cohesion effects.
\end{abstract}

\section{Introduction}

Alluvial rivers develop planform morphologies that extend between two well defined end-members: braided or meandering (e.g. Mackin, 1948; Leopold et al., 1957; Schumm, 1977). In meandering channels, flow is confined in a single thread, whereas braided channels are composed of multiple intertwined threads (Schumm, 1977). Individual threads in braided rivers appear to be morphologically comparable (Church, 1975; Ashmore, 1982; Mosley, 1983; Bridge and Gabel, 1992; Ferguson, 1993; Bridge, 1993), and laboratory experiments agree with this observation (Hundey and Ashmore, 2009; Reitz et al., 2014). This suggests that a braided channel is a collection of distinct, but morphologically similar threads that share common regime equations.

Following the works mentioned above we consider a braided channel composed of $n$ threads of individual width $w_{i}$ and formative discharge $Q_{i}$. All threads share a common regime relation of the form

$w_{i}=\alpha_{w} Q_{i}^{\beta_{w}}$,

where $\alpha_{w}$ and $\beta_{w}$ are two constants. If the exponent $\beta_{w}$ is different from one, the regime equation is non-linear (Church,
1975; Mosley, 1983; Parker et al., 2007), and the regime relation for the entire braided channel, obtained by summing over the widths of individual threads, is different from Eq. (1).

Accordingly, we need to study threads individually to better understand the reach-averaged hydraulic geometries of braided rivers. This understanding could then be used for the study of river pattern development or for the prediction of discharge from satellite images (Van den Berg, 1995; Ashmore and Sauks, 2006; Smith and Pavelsky, 2008; Métivier and Barrier, 2012; Passalacqua et al., 2013; Marra et al., 2014). As a first step, it would therefore be instructive to compare the morphology of braided threads to that of meandering threads to know if the latter could provide a useful analogue of the former. Indeed, the mechanisms by which a single-thread channel develops its morphology have been extensively studied (Glover and Florey, 1951; Henderson, 1963; Parker, 1978; Parker et al., 2007; Seizilles et al., 2013). The research question then is can we extend these results to the individual threads of braided rivers?

To answer this question, we need to compare single-thread rivers with braided rivers with all other boundary conditions being equal. A look at the available literature shows that 
the publicly available databases (Brownlie, 1981a, b; Hedman and Osterkamp, 1982; Osterkamp and Hedman, 1982; Church and Rood, 1983; Van den Berg, 1995) do not allow for such a comparison, as the morphology of braided rivers is always considered at the scale of the entire channel width. Here, we address this issue and report the first set of measurements on individual threads in sand-bed-braided and meandering rivers. We perform our measurements on the braided and meandering reaches of the Kosi River and isolated meandering rivers located on the Kosi fan surface (North Bihar, India). All of these threads spread over the same megafan composed of homogeneous sandy deposits and are submitted to the same climate.

After a description of the field site (Sect. 2), we present measurements of width, depth and water discharge from 34 braided and 17 meandering threads (Sect. 3). Grain size, slope and sinuosity are also measured. We then provide (Sect. 4) an analysis of the data sets that addresses the statistical distributions of the morphological characteristics of thread populations. We further discuss (Sect. 5) how observed trends can be understood with the help of a simple theoretical framework. Finally, we discuss (Sect. 6) the limitations of this new database, and suggest further improvements.

\section{The Kosi River megafan}

The megafan of the Kosi River spans over $10351 \mathrm{~km}^{2}$ of the northern Bihar plain, India (Fig. 1). It results from the deposition of Himalayan sediments by the Kosi River. These sediments are essentially composed of quartz grains with a median size of $\sim 300 \mu \mathrm{m}$ in the proximal part of the fan, and $\sim 200 \mu \mathrm{m}$ in its distal part. A series of avulsions has built an almost conical fan surface, which longitudinal slope varies from about $8 \times 10^{-4}$ at the apex, to $6 \times 10^{-5}$ near the toe (Gole and Chitale, 1966; Wells and Dorr, 1987; Singh et al., 1993; Chakraborty et al., 2010).

Today, the main flow of the Kosi River is located at the western flank of the fan, where it is confined by an artificial embankment. Within this embankment, the Kosi River is braided along most of its course, and turns into a meandering channel near its confluence with the Ganga River (Seni, 1980; Gohain, 1990; Singh et al., 1993; DeCelles and Cavazza, 1999; Chakraborty et al., 2010). At present there is no explanation for such a change in river morphology.

In addition to the Kosi River itself, tens of isolated singlethread rivers spread across the entire fan surface. These rivers appear in the remnants of the Kosi River past courses. Most of them are fed either by groundwater or seepage from the Kosi River (Chakraborty et al., 2010; Sinha et al., 2013). Hereafter, we refer to them as isolated channels. All isolated channels are single thread and meandering.

\section{Methodology}

\subsection{Measurements}

Our field measurements consist of the velocity profiles, depth profiles, grain size and free-surface slope of threads of the main Kosi channel and of isolated channels. We have also measured the sinuosity of threads from both type of channels using Landsat 8 satellite images.

\subsubsection{Velocity and depth profiles}

To compare braided and meandering threads, we need measurements of their hydraulic geometry, grain size and discharge. Therefore, during the monsoon of 2012, and just after the monsoon of 2013, we collected the width, depth and discharge of 51 threads of the Kosi River megafan. In North Bihar, the formative discharge is likely to occur during the monsoon (Fig. 2).

When the water depth was sufficient, we used an acoustic Doppler current profiler (ADCP) to measure the water velocity profile of the channel (RD Instruments RioGrande 1.2 MHz). This instrument features four transducers with a fixed beam angle of $20^{\circ}$ with respect to the vertical (Morlock, 1996; Simpson, 2001; Parsons et al., 2005). The ADCP emits acoustic pulses through the water column, and records the pulses reflected by scatterers, such as bubbles or sediment particles. Its beams are divided into equal-size bins of 5 to $25 \mathrm{~cm}$. Based on the Doppler frequency shift, it computes the mean velocity of each bin (Rennie and Villard, 2004; Parsons et al., 2005; Chauvet et al., 2014). In addition, we complemented the ADCP with an external echo-sounder to record the water depth (Tritech) (Richardson and Thorne, 2001). We then computed the flow discharge and hydraulic geometry from these measurements.

For this study, we levelled 44 ADCP transects: 34 from braided threads and 10 from meandering threads (Tables 2 and 3). To acquire these transects, we deployed the ADCP on an inflatable motor boat and cross the channel perpendicularly to the flow direction. We used ADCP in bottom-track mode to measure the flow velocity. We used a hand-held GPS to records the boat's position, which provides a horizontal positional accuracy of $\sim 10 \mathrm{~m}$. Szupiany et al. (2007) showed that single transects were sufficient to measure the discharge through a section, but that more transects were needed in order to acquire a more precise knowledge of the flow structure. Since our objective here is to obtain the flow discharge passing through a cross-section, we did not try to collect more then two consecutive transects. Therefore, our measurements are restricted to average flow velocities and total discharges. The average flow velocity was calculated from the good ensembles (i.e. valid records) and then extrapolated to the entire cross-section to estimate the total discharge. To assess the measurement uncertainty, we took advantage of $20 \mathrm{sec}-$ tions for which we had two consecutive transects. One sec- 


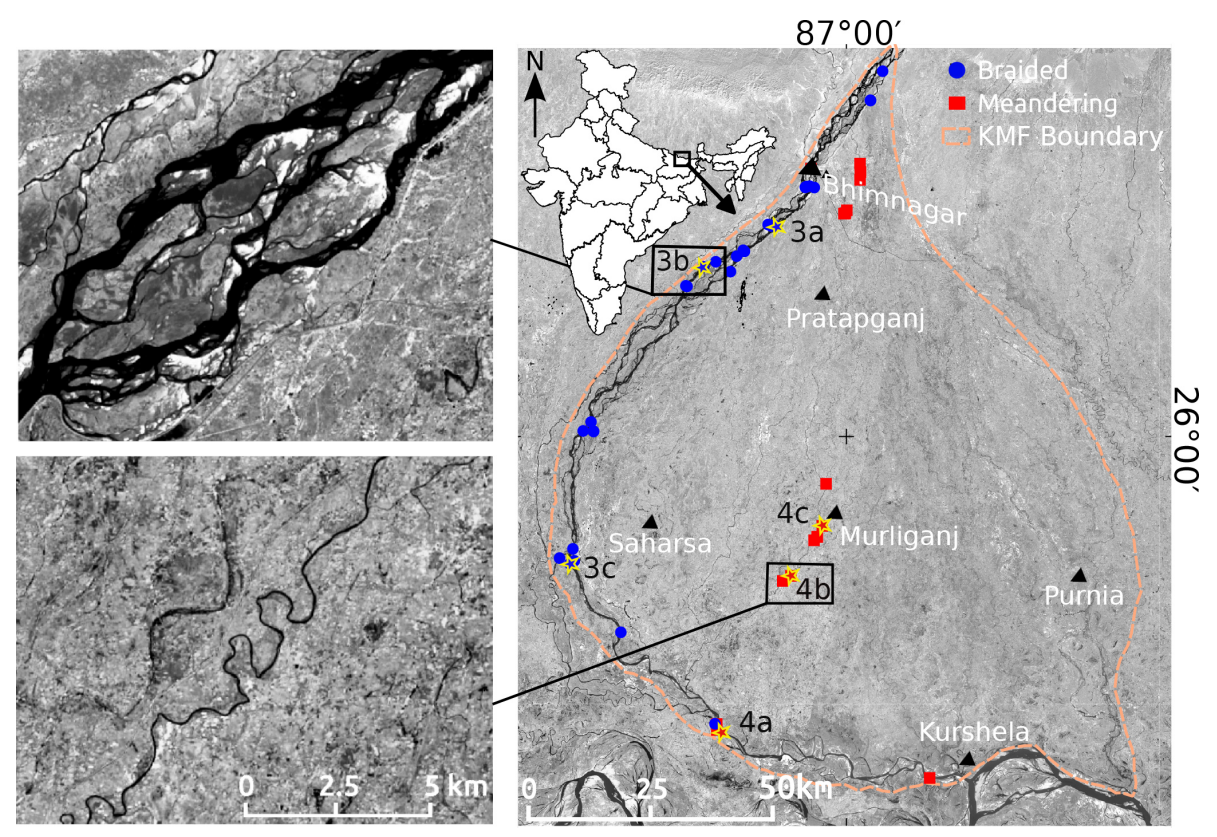

Figure 1. The Kosi megafan (KMF) boundary shown on Landsat 8 satellite image (acquired on 11 November 2013). Red and blue points on the image show the locations of cross-section measurements. Blue (a-c) and red (a-c) star marks highlighted with yellow boundaries show the location of braided and meandering cross-sections of Figs. 3 and 4. Top and bottom left images show the typical pattern of multiple-thread braided and single-thread meandering channels at the same scale (source of Landsat images: US Geological Survey).

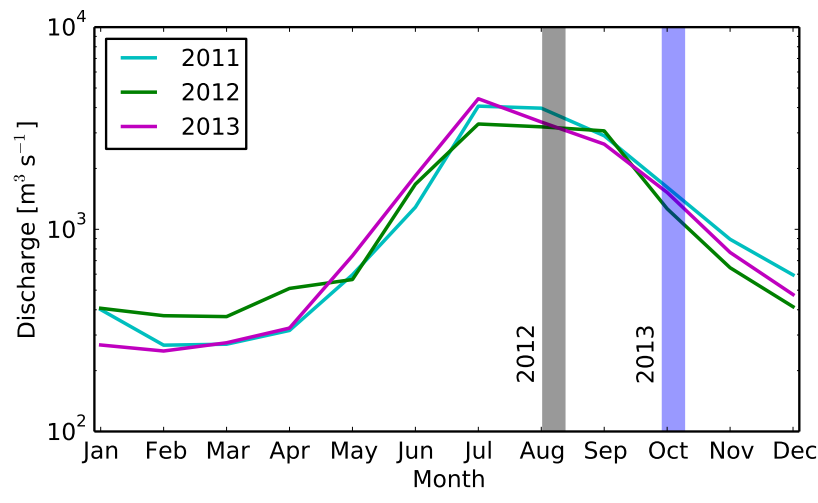

Figure 2. Average monthly water discharge of the Kosi River (measured at the Kosi barrage, Bhimnagar, during three successive years). Gray and blue shades indicate our measurements (source: Investigation and Research Division, Kosi project, Birpur).

tion was used to derive the flow discharge and velocity and the other was used to calculate the variability of the measurement. Based on these redundant measurements, we found a relative error on the mean value of about $10,15,5$ and $12 \%$ for width, depth, mean velocity and discharge respectively. Possible sources of uncertainty include variability in boat position and missing ensembles during the acquisition process.

We were unable to access the smaller threads by boat at seven different locations. We therefore measured their characteristics manually (Table 3). To do so, we first measured the water depth every $0.5 \mathrm{~m}$ across the channel with a wading rod. This method yields a precision of about $2 \mathrm{~cm}$. We then measured the surface velocity of the flow by dropping a float and measuring its travel time over a fixed distance (10 to $20 \mathrm{~m}$ ), and repeated this procedure three times at the same location. Measured velocities vary by less then $11 \%$ around the mean value. We then multiplied the mean surface velocity by 0.6 to approximate the depth-averaged velocity (Sanders, 1998).

\subsubsection{Grain size, slope and sinuosity}

We measured the grain-size distribution (Tables 2 and 3) at locations close to hydraulic measurement sites. Sediment samples were sieved into seven size categories, ranging from 0.074 to $0.841 \mathrm{~mm}$, and the median grain size $d_{\mathrm{s}}$ was calculated from the frequency distributions.

Measurements of the longitudinal slope of four braided and two meandering threads are available (Table 4). To measure the slope of a thread, we used a real-time kinematic GPS on the boat (Trimble-R8), and travel downstream over at least $7 \mathrm{~km}$. This yields an uncertainty of less then $10 \%$.

Finally, we calculated the sinuosity along four different meandering threads and two braided threads from the active Kosi channel. For this we used Landsat 8 images (spatial resolution of $30 \mathrm{~m}$ ). The sinuosity is the ratio between the distance along the stream divided by the shortest distance between two points along a thread. The procedure was then repeated along the entire thread length. To evaluate the in- 
fluence of the measurement distance on the results, we then calculated the sinuosity over a distance of 10, 20, 50 and 100 times the average thread width.

\subsection{Cross-section processing}

The cross-sections from the braided reach of the Kosi River (Fig. 3), exhibit a more complex profile than those of singlethread channels (Fig. 4). Different threads are visible, separated by regions where the flow depth is very shallow (Fig. 3). Such areas correspond to the bars separating different threads. Our objective is to compare the morphology of meandering threads of the Kosi fan surface to that of the braided reach of the Kosi River. We thus need to divide the braided section into elements comparable to single threads. Doing this, however, is a somewhat arbitrary procedure, if only because the wetted area depends on the river stage (Mosley, 1983; Ashmore, 2013).

To split a braided section into different threads, we automatically detect bars. For all points on the cross-section, we calculate the ratio between the flow depth to the maximum flow depth of the entire section. When this ratio is below a threshold value a point is considered part of a bar. When the ratio is above the threshold, a point is considered part of a thread. The procedure is repeated along the entire section to identify bars and threads (Fig. 3). We test different threshold values of 10,15 and $20 \%$ of the maximum flow depth. With 15 and $20 \%$ thresholds, extracted threads and bar areas are in agreement with visual observations. For a $10 \%$ threshold, this is not the case. The choice of $20 \%$ threshold over $15 \%$ does not lead to any significant change in the final output. Therefore, we use a threshold value of $15 \%$ of the maximum flow depth to detect bars and distinguish threads. We then calculate the morphological characteristics of individual braided threads from the velocity and bed topography profiles.

\section{Results}

\subsection{Sinuosity}

As most of the meandering channels are isolated channels which occupy former channels of the main Kosi River, these residual channels could have an inherited morphology. However, Fig. 1 suggests that this is not the case as isolated channels often develop a highly meandering pattern that is not usually observed in braided systems (Schumm, 1977).

We perform a Kolmogorov-Smirnov test to check whether the distributions of sinuosity of threads from the meandering channels differ from those from the main Kosi braided threads (note that sinuosity is not normally distributed and only non-parametric tests apply, Scherrer, 1984). Kolmogorov-Smirnov tests show that the distributions are different, to the $95 \%$ level of confidence, at all length scales. As average sinuosity of meandering channels is higher than
Table 1. Linear regressions on the $\log _{10}$ of width, depth and aspect ratios of threads as functions of discharge. The confidence level is $95 \%$. RMA: reduced major axis regression; OLS: ordinary least square. $\sigma_{\beta}$ stands for confidence interval on the slope of the regres$\operatorname{sion} \beta$.

\begin{tabular}{|c|c|c|c|c|c|}
\hline \multicolumn{6}{|c|}{ Width: $\log _{10}\left(W / d_{\mathrm{S}}\right)=\beta_{w} \log _{10} Q_{*}+\alpha_{w}$} \\
\hline Thread type & Correlation & $\beta_{w}$ & $\alpha_{w}$ & $\sigma_{\beta_{w}}$ & $R^{2}$ \\
\hline Total population & RMA & 0.58 & -0.55 & 0.04 & 0.77 \\
\hline Meandering threads & RMA & 0.52 & 0.13 & 0.06 & 0.8 \\
\hline Braided threads & RMA & 0.66 & -1.42 & 0.06 & 0.69 \\
\hline \multicolumn{6}{|c|}{ Depth: $\log _{10}\left(H / d_{\mathrm{s}}\right)=\beta_{h} \log _{10} Q_{*}+\alpha_{h}$} \\
\hline Thread type & Correlation & $\beta_{h}$ & $\alpha_{h}$ & $\sigma_{\beta_{h}}$ & $R^{2}$ \\
\hline Total population & RMA & 0.35 & 0.0 & 0.03 & 0.58 \\
\hline Meandering threads & RMA & 0.39 & -0.19 & 0.04 & 0.8 \\
\hline Braided threads & RMA & 0.36 & -0.11 & 0.05 & 0.44 \\
\hline \multicolumn{6}{|c|}{ Aspect ratio: $\log _{10}(W / H)=\beta_{w / h} \log _{10} Q_{*}+\alpha_{w / h}$} \\
\hline Thread type & Correlation & $\beta_{w / h}$ & $\alpha_{w / h}$ & $\sigma_{\beta_{w / h}}$ & $R^{2}$ \\
\hline Total population & OLS & 0.24 & -0.77 & 0.13 & 0.2 \\
\hline Meandering & OLS & \multicolumn{4}{|c|}{ Correlation is not significant } \\
\hline Braided & OLS & 0.3 & -1.41 & 0.22 & 0.19 \\
\hline
\end{tabular}

1.2 , we hereafter consider the threads from the isolated channels as meandering threads.

\subsection{Threads' morphology}

Once we have calculated the morphological characteristics of all braided and meandering threads, we plot them together against the corresponding water discharge. Figure 5 shows dimensionless width $\left(W / d_{\mathrm{s}}\right)$, flow depth $\left(H / d_{\mathrm{s}}\right)$ and slope $(S)$ as a function of the dimensionless discharge $Q_{*}=$ $Q / \sqrt{g d_{\mathrm{s}}^{5}}$ (where $d_{\mathrm{s}}$ and $g=9.81 \mathrm{~m} \mathrm{~s}^{-2}$ are the median grain size and the acceleration of gravity).

Not surprisingly, the size of threads increases with discharge. Conversely, their slope $S$ decreases with discharge. We observe no obvious difference between meandering and braided threads: despite considerable scatter, all data points seem to gather around a single power law. This observation suggests that meandering and braided threads share common regime relations (Lacey, 1930; Parker et al., 2007). To address this further, we perform a reduced major axis regression (RMA) on the logarithm of the distributions of width and depth (Sokal and Rohlf, 1995; Scherrer, 1984) (Table 1). The correlations of width and depth with discharge are significant at the $95 \%$ level of confidence. The quality of the regression is higher for width $\left(R^{2} \sim 0.7-0.8\right)$ than for depth $\left(R^{2} \sim 0.4-0.8\right)$

We now test the following null hypothesis: the regressions obtained for the width and depth of meandering and braided threads are not significantly different. It appears that the regime relationships of meandering and braided threads of the Kosi megafan cannot be differentiated within the $95 \%$ level of confidence. 
Table 2. Hydraulic geometry and water discharge data measured on threads of braided channels.

\begin{tabular}{|c|c|c|c|c|c|c|c|c|c|c|}
\hline Id & Year & River & Instrument & $\begin{array}{l}\text { Width } \\
\text { (m) }\end{array}$ & $\begin{array}{r}\text { Depth } \\
(\mathrm{m})\end{array}$ & $\begin{array}{l}\text { Velocity } \\
\left(\mathrm{m} \mathrm{s}^{-1}\right)\end{array}$ & $\begin{array}{r}\text { Discharge } \\
\left(\mathrm{m}^{3} \mathrm{~s}^{-1}\right)\end{array}$ & $\begin{array}{r}\text { Grain size } \\
(\mu \mathrm{m})\end{array}$ & $\begin{array}{r}\text { Latitude } \\
\text { (dd) }\end{array}$ & $\begin{array}{r}\text { Longitude } \\
\text { (dd) }\end{array}$ \\
\hline 1 & 2012 & Main Kosi & ADCP & 436 & 2.7 & 1.3 & 1532 & 300 & 26.7016 & 87.0743 \\
\hline 2 & 2012 & Main Kosi & $\mathrm{ADCP}$ & 183 & 2.5 & 0.8 & 335 & 300 & 26.6486 & 87.0496 \\
\hline 3 & 2012 & Main Kosi & $\mathrm{ADCP}$ & 170 & 3.5 & 0.7 & 387 & 300 & 26.6488 & 87.0491 \\
\hline 4 & 2012 & Main Kosi & $\mathrm{ADCP}$ & 29 & 2.0 & 0.8 & 45 & 200 & 26.0475 & 86.4846 \\
\hline 5 & 2012 & Main Kosi & $\mathrm{ADCP}$ & 639 & 2.4 & 1.4 & 2197 & 200 & 26.0475 & 86.4844 \\
\hline 6 & 2012 & Main Kosi & $\mathrm{ADCP}$ & 647 & 2.3 & 1.4 & 2102 & 200 & 26.0481 & 86.4633 \\
\hline 7 & 2013 & Main Kosi & $\mathrm{ADCP}$ & 78 & 1.1 & 0.5 & 42 & 270 & 26.491 & 86.9161 \\
\hline 8 & 2013 & Main Kosi & $\mathrm{ADCP}$ & 200 & 3.0 & 1.3 & 808 & 270 & 26.4921 & 86.9182 \\
\hline 9 & 2013 & Main Kosi & $\mathrm{ADCP}$ & 182 & 3.0 & 1.4 & 749 & 270 & 26.4921 & 86.9184 \\
\hline 10 & 2013 & Main Kosi & $\mathrm{ADCP}$ & 78 & 1.1 & 0.5 & 39 & 270 & 26.4912 & 86.916 \\
\hline 11 & 2013 & Main Kosi & $\mathrm{ADCP}$ & 171 & 0.7 & 0.4 & 55 & 270 & 26.493 & 86.9249 \\
\hline 12 & 2013 & Main Kosi & $\mathrm{ADCP}$ & 282 & 1.1 & 0.9 & 276 & 270 & 26.4906 & 86.9343 \\
\hline 13 & 2013 & Main Kosi & $\mathrm{ADCP}$ & 113 & 2.0 & 1.1 & 256 & 245 & 26.4234 & 86.8398 \\
\hline 14 & 2013 & Main Kosi & $\mathrm{ADCP}$ & 151 & 2.7 & 1.6 & 640 & 245 & 26.4207 & 86.8464 \\
\hline 15 & 2013 & Main Kosi & $\mathrm{ADCP}$ & 181 & 2.6 & 0.5 & 249 & 245 & 26.4224 & 86.8529 \\
\hline 16 & 2013 & Main Kosi & $\mathrm{ADCP}$ & 363 & 1.9 & 1.1 & 730 & 220 & 26.3557 & 86.733 \\
\hline 17 & 2013 & Main Kosi & $\mathrm{ADCP}$ & 146 & 1.0 & 0.9 & 127 & 220 & 26.311 & 86.6744 \\
\hline 18 & 2013 & Main Kosi & $\mathrm{ADCP}$ & 132 & 1.9 & 1.3 & 326 & 220 & 26.3119 & 86.6719 \\
\hline 19 & 2013 & Main Kosi & $\mathrm{ADCP}$ & 200 & 1.7 & 0.6 & 220 & 220 & 26.3466 & 86.7071 \\
\hline 20 & 2013 & Main Kosi & $\mathrm{ADCP}$ & 58 & 3.5 & 1.1 & 228 & 245 & 26.3765 & 86.789 \\
\hline 21 & 2013 & Main Kosi & $\mathrm{ADCP}$ & 568 & 2.3 & 1.1 & 1374 & 245 & 26.3748 & 86.7913 \\
\hline 22 & 2013 & Main Kosi & $\mathrm{ADCP}$ & 56 & 3.5 & 1.2 & 235 & 245 & 26.3763 & 86.7889 \\
\hline 23 & 2013 & Main Kosi & $\mathrm{ADCP}$ & 504 & 2.2 & 1 & 1094 & 245 & 26.3748 & 86.7916 \\
\hline 24 & 2013 & Main Kosi & $\mathrm{ADCP}$ & 144 & 0.9 & 0.5 & 66 & 245 & 26.3659 & 86.7756 \\
\hline 25 & 2013 & Main Kosi & $\mathrm{ADCP}$ & 118 & 1.9 & 0.9 & 204 & 220 & 26.3379 & 86.7632 \\
\hline 26 & 2013 & Main Kosi & $\mathrm{ADCP}$ & 428 & 2.7 & 0.8 & 943 & 180 & 25.8341 & 86.4433 \\
\hline 27 & 2013 & Main Kosi & $\mathrm{ADCP}$ & 145 & 1.9 & 1 & 274 & 180 & 25.8173 & 86.4162 \\
\hline 28 & 2013 & Main Kosi & $\mathrm{ADCP}$ & 254 & 1.2 & 0.8 & 226 & 180 & 25.8123 & 86.4464 \\
\hline 29 & 2013 & Main Kosi & $\mathrm{ADCP}$ & 335 & 0.9 & 0.6 & 193 & 180 & 25.809 & 86.4417 \\
\hline 30 & 2013 & Main Kosi & $\mathrm{ADCP}$ & 217 & 2.0 & 0.8 & 363 & 180 & 25.8072 & 86.4372 \\
\hline 31 & 2013 & Main Kosi & $\mathrm{ADCP}$ & 38 & 2.2 & 1.1 & 87 & 200 & 26.0474 & 86.4845 \\
\hline 32 & 2013 & Main Kosi & $\mathrm{ADCP}$ & 996 & 2.3 & 1.3 & 2846 & 200 & 26.0644 & 86.4793 \\
\hline 33 & 2013 & Main Kosi & $\mathrm{ADCP}$ & 119 & 4.3 & 0.8 & 408 & 200 & 25.5176 & 86.7332 \\
\hline 34 & 2013 & Main Kosi & $\mathrm{ADCP}$ & 370 & 2.0 & 1 & 713 & 95 & 25.6831 & 86.5416 \\
\hline
\end{tabular}

We perform the same analysis for the aspect ratio of threads (Table 1). Because the correlations are very weak and the correlation coefficients small, RMA is not applicable any more and only ordinary least square regressions (OLS) apply (e.g Scherrer, 1984; Parker et al., 2007). Within the $95 \%$ level of confidence, aspect ratios of the meandering threads exhibit no relationship with discharge, whereas those of braided threads do exhibit a weak $\left(R^{2}=0.2\right)$ correlation with discharge. However, with the same level of confidence, the regressions performed on both thread types are not significantly different. The aspect ratios thus seem to be almost detrended from discharge.

The regressions on slopes are not significant within the $95 \%$ level of confidence and no conclusion can be drawn from such a small data set.

\section{Discussion}

The large scatter of our data do not allow one to draw definitive conclusions about the exponents of the regressions. However, the results presented here unambiguously show that meandering and braided threads share a common regime relationship with discharge. To our knowledge, this result has never been evidenced before.

However, empirical regressions suggest that the aspect ratios of threads are almost independent of discharge although the exponents of the regime equations might differ slightly for width and depth (Fig. 6). To further understand the potential detrending of the aspect ratio, we now compare our data set with a physically based theory of river regime. One of the simplest set of regime relations for single-thread alluvial channels derives from the threshold hypothesis (Glover and Florey, 1951; Henderson, 1963; Seizilles et al., 2013). 
Table 3. Hydraulic geometry and water discharge data measured on the single thread of meandering channels.

\begin{tabular}{|c|c|c|c|c|c|c|c|c|c|c|}
\hline Id & Year & River & Instrument & $\begin{array}{l}\text { Width } \\
\text { (m) }\end{array}$ & $\begin{array}{r}\text { Depth } \\
(\mathrm{m})\end{array}$ & $\begin{array}{l}\text { Velocity } \\
\left(\mathrm{m} \mathrm{s}^{-1}\right)\end{array}$ & $\begin{array}{r}\text { Discharge } \\
\left(\mathrm{m}^{3} \mathrm{~s}^{-1}\right)\end{array}$ & $\begin{array}{r}\text { Grain size* } \\
(\mu \mathrm{m})\end{array}$ & $\begin{array}{r}\text { Latitude } \\
(\mathrm{dd})\end{array}$ & $\begin{array}{r}\text { Longitude } \\
(\mathrm{dd})\end{array}$ \\
\hline 35 & 2013 & Main Kosi & $\mathrm{ADCP}$ & 345 & 5.4 & 1.3 & 2462 & 200 & 25.5111 & 86.736 \\
\hline 36 & 2013 & Main Kosi & ADCP & 558 & 4.6 & 1.1 & 2819 & 200 & 25.5065 & 86.7371 \\
\hline 37 & 2013 & Main Kosi & $\mathrm{ADCP}$ & 559 & 2.2 & 0.9 & 2584 & 260 & 25.4195 & 87.1689 \\
\hline 38 & 2013 & Isolated Channel & $\mathrm{ADCP}$ & 60 & 2.4 & 0.8 & 111 & 260 & 25.8768 & 86.9508 \\
\hline 39 & 2013 & Isolated Channel & $\mathrm{ADCP}$ & 68 & 2.4 & 0.7 & 113 & 260 & 25.857 & 86.9407 \\
\hline 40 & 2013 & Isolated Channel & $\mathrm{ADCP}$ & 65 & 2.6 & 0.7 & 114 & 260 & 25.857 & 86.9406 \\
\hline 41 & 2013 & Isolated Channel & $\mathrm{ADCP}$ & 68 & 5.3 & 0.6 & 113 & 200 & 25.8507 & 86.9341 \\
\hline 42 & 2013 & Isolated Channel & $\mathrm{ADCP}$ & 53 & 1.4 & 0.8 & 57 & 270 & 25.9532 & 86.9586 \\
\hline 43 & 2013 & Isolated Channel & $\mathrm{ADCP}$ & 52 & 3.8 & 0.6 & 123 & 250 & 25.7861 & 86.8871 \\
\hline 44 & 2013 & Isolated Channel & $\mathrm{ADCP}$ & 38 & 3.5 & 0.7 & 98 & 250 & 25.7769 & 86.8705 \\
\hline 45 & 2013 & Isolated Channel & Float & 30 & 0.7 & 0.4 & 9 & 210 & 26.5186 & 87.0286 \\
\hline 46 & 2013 & Isolated Channel & Float & 72 & 0.4 & 0.6 & 16 & 210 & 26.5339 & 87.0279 \\
\hline 47 & 2013 & Isolated Channel & Float & 50 & 0.5 & 0.4 & 9 & 210 & 26.5045 & 87.028 \\
\hline 48 & 2013 & Isolated Channel & Float & 32 & 0.8 & 0.3 & 8 & 210 & 26.5187 & 87.0288 \\
\hline 49 & 2013 & Isolated Channel & Float & 51 & 1.3 & 0.2 & 11 & 210 & 26.4438 & 86.9978 \\
\hline 50 & 2013 & Isolated Channel & Float & 40 & 1.5 & 0.3 & 18 & 210 & 26.4433 & 86.995 \\
\hline 51 & 2013 & Isolated Channel & Float & 73 & 0.7 & 0.2 & 9 & 210 & 26.4493 & 87.0009 \\
\hline
\end{tabular}

* Median $\left(d_{50}\right)$ grain size.

Table 4. Longitudinal water surface slope and corresponding water discharge.

\begin{tabular}{|c|c|c|c|c|c|c|c|c|c|}
\hline \multirow[t]{2}{*}{$\mathrm{Id}^{*}$} & \multirow[t]{2}{*}{ Year } & \multirow[t]{2}{*}{ River } & \multirow[t]{2}{*}{ Thread type } & \multirow[t]{2}{*}{ Slope } & \multirow{2}{*}{$\begin{array}{l}\text { Discharge } \\
\left(\mathrm{m}^{3} \mathrm{~s}^{-1}\right)\end{array}$} & \multicolumn{2}{|c|}{ Starting point } & \multicolumn{2}{|c|}{ End point } \\
\hline & & & & & & $\begin{array}{r}\text { Latitude } \\
\text { (dd) }\end{array}$ & $\begin{array}{r}\text { Longitude } \\
\text { (dd) }\end{array}$ & $\begin{array}{r}\text { Latitude } \\
\text { (dd) }\end{array}$ & $\begin{array}{r}\text { Longitude } \\
\text { (dd) }\end{array}$ \\
\hline 17 & 2013 & Main Kosi & Braided & $4.6 \times 10^{-4}$ & 127 & 26.375 & 86.787 & 26.310 & 86.672 \\
\hline 20 & 2013 & Main Kosi & Braided & $4.7 \times 10^{-4}$ & 228 & 26.490 & 86.935 & 26.363 & 86.786 \\
\hline 32 & 2013 & Main Kosi & Braided & $2.2 \times 10^{-4}$ & 2846 & 26.057 & 86.469 & 25.886 & 86.433 \\
\hline 34 & 2013 & Main Kosi & Braided & $1.9 \times 10^{-4}$ & 713 & 25.715 & 86.500 & 25.657 & 86.529 \\
\hline 38 & 2013 & Main Kosi & Single & $4.8 \times 10^{-5}$ & 2584 & 25.419 & 87.170 & 25.410 & 87.249 \\
\hline 43 & 2013 & Isolated Channel & Single & $4.2 \times 10^{-4}$ & 57 & 25.997 & 86.926 & 25.954 & 86.957 \\
\hline
\end{tabular}

* Refer to the Tables 2 and 3

This theory assumes that the channel sediment is exactly at the threshold of motion. In other words, the combination of gravity and flow-induced shear stress hardly suffices to displace a sediment grain. Since the Kosi threads are likely to transport sediment, we do not expect the threshold theory to match exactly our observations. However, we discuss its ability to detrend river morphology with respect to water discharge.

\subsection{Scaling laws for the Kosi fan threads}

For a specific discharge, the balance of forces on the bed and banks at the threshold of motion sets the width, the depth and the longitudinal slope of a thread. The corresponding regime relations were first derived by Glover and Florey (1951) and Henderson (1963). In dimensionless form they read (Seizilles, 2013):

$$
\begin{aligned}
& \frac{W}{d_{s}}=\frac{\pi}{\sqrt{\mu}}\left(\frac{\theta_{t}\left(\rho_{s}-\rho\right)}{\rho}\right)^{-1 / 4} \sqrt{\frac{3 C_{f}}{2^{3 / 2} \mathcal{K}[1 / 2]}} Q_{*}^{1 / 2} \\
& \frac{H}{d_{s}}=\frac{\sqrt{\mu}}{\pi}\left(\frac{\theta_{t}\left(\rho_{s}-\rho\right)}{\rho}\right)^{-1 / 4} \sqrt{\frac{3 \sqrt{2} C_{f}}{\mathcal{K}[1 / 2]}} Q_{*}^{1 / 2} \\
& S=\mu^{1 / 2}\left(\frac{\theta_{t}\left(\rho_{s}-\rho\right)}{\rho}\right)^{5 / 4} \sqrt{\frac{\mathcal{K}[1 / 2] 2^{3 / 2}}{3 C_{f}}} Q_{*}^{-1 / 2}
\end{aligned}
$$

where $Q_{*}=Q / \sqrt{g d_{\mathrm{s}}^{5}}$ is the dimensionless water discharge (Parker, 1979; Parker et al., 2007; Wilkerson and Parker, 2010). For simplicity, we follow Glover and Florey (1951) and assume that the Chézy friction factor $C_{\mathrm{f}} \approx 0.1$ is independent of the flow depth. All other parameters are approximately constant for the threads of the Kosi River fan: $\theta_{t} \approx 0.3$ is the threshold Shields parameter, $\mu \approx 0.7$ is the 

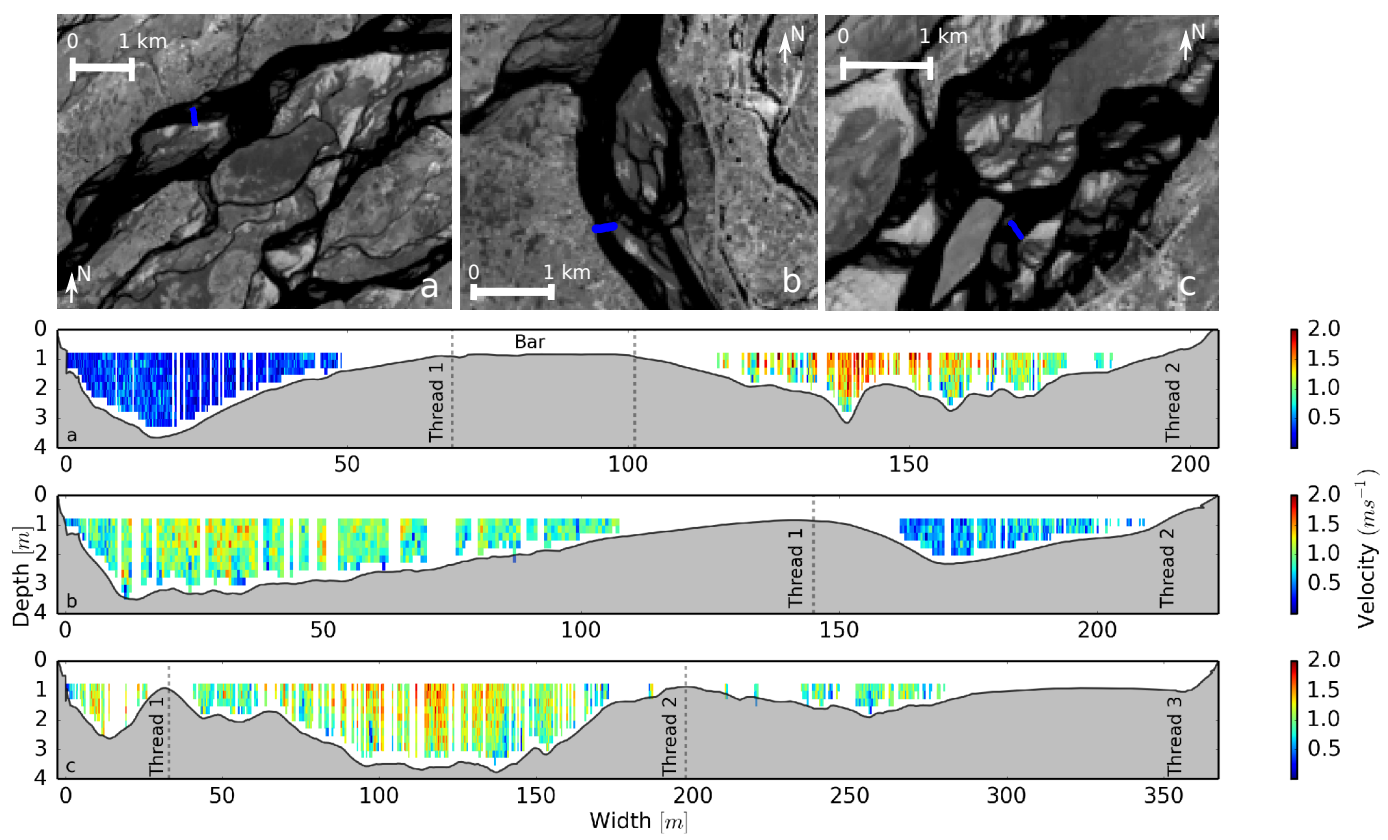

Figure 3. ADCP-measured velocity profile across braided channels of the Kosi River. The location of channel reaches are shown on Landsat 8 images (acquired on 11 November 2013, 1 month after the measurements). The locations of the reaches here marked by blue bands (a-c) are shown in Fig. 1 as blue stars with yellow boundaries. Dotted vertical lines in the figures illustrate the division of a cross-section into different threads.
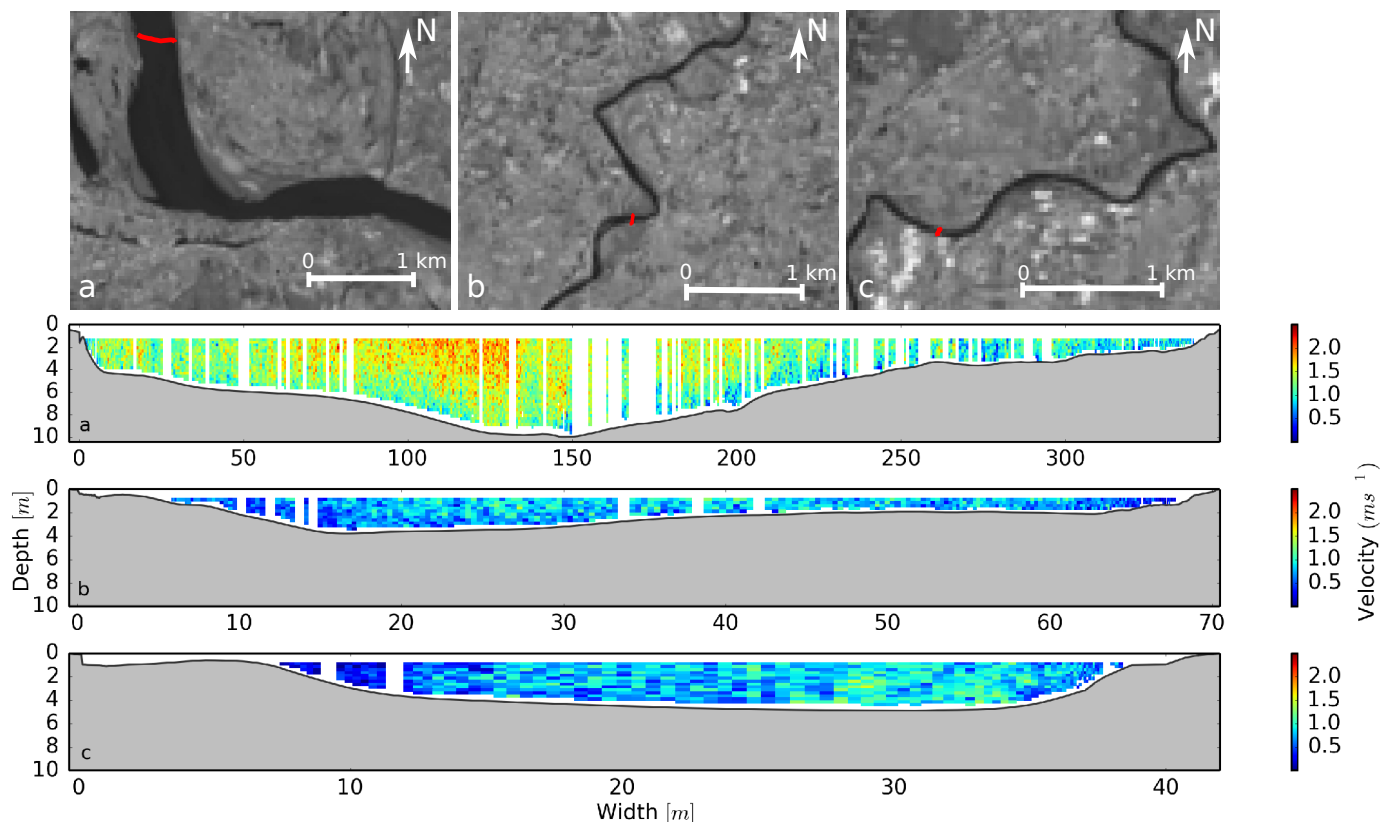

Figure 4. ADCP-measured velocity profile across meandering channels of the Kosi River. The location of channel reaches are shown on Landsat 8 images (acquired on 11 November 2013, 1 month after the measurements). The locations of the reaches here marked by red bands $(\mathbf{a}-\mathbf{c})$ are shown in Fig. 1 as red stars with yellow boundaries.

Coulomb's coefficient of friction, $d_{s}$ is the sediment median grain size, $\rho \approx 1000 \mathrm{~kg} \mathrm{~m}^{-3}$ is the density of water and $\rho_{s} \approx$ $2650 \mathrm{~kg} \mathrm{~m}^{-3}$ is the density of quartz. Finally, $\mathcal{K}(1 / 2) \approx 1.85$ is the elliptic integral of the first kind.
We then compare our data set to the threshold theory (green line in Fig. 7). The predicted trends seem to agree with the data. However, the threads are wider (by of factor of about 2), significantly shallower (about a factor of 8) 

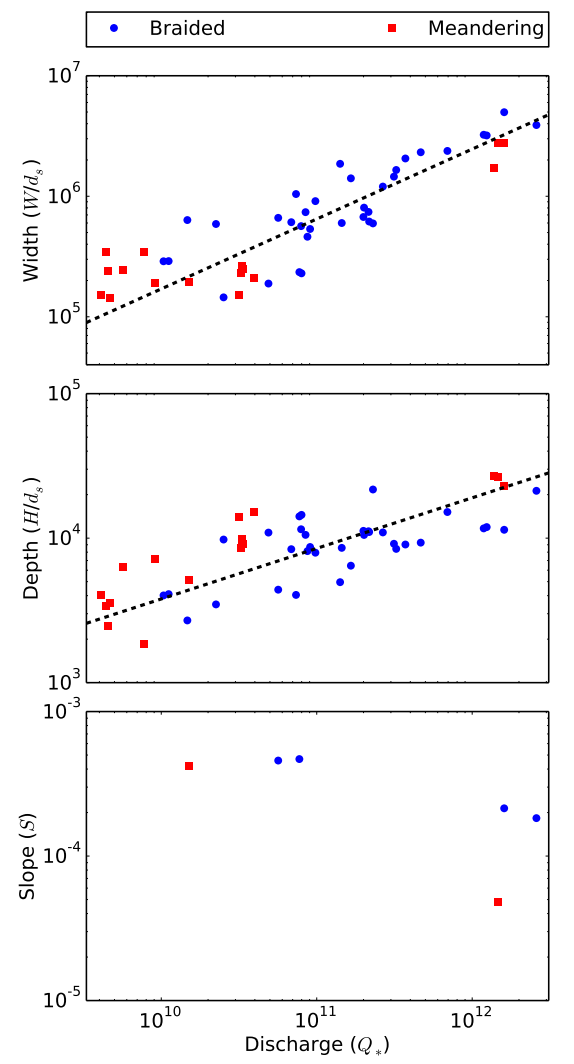

Figure 5. Dimensionless width, depth and slope of the threads as functions of the dimensionless water discharge. Empirical regime relationships obtained by RMA are shown in dashed lines (see Table 1 for details).

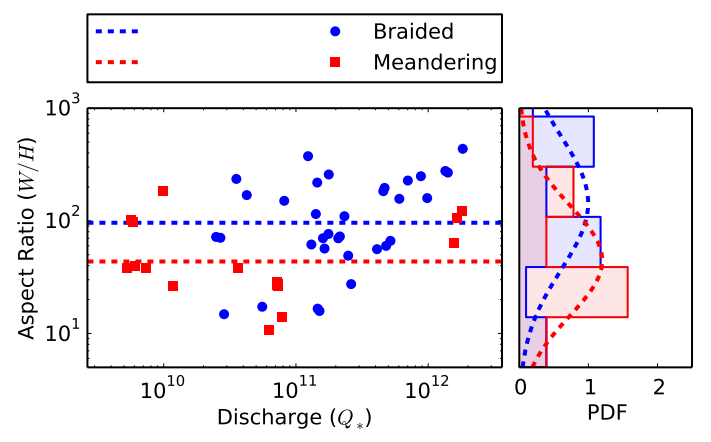

Figure 6. Aspect ratio $(W / H)$ of the threads as a function of the dimensionless water discharge $\left(Q_{*}\right)$. Blue and red dashed lines show the average aspect ratio. Right: probability density functions.

and about 25 times steeper then predicted. This discrepancy is not surprising since the threshold hypothesis corresponds to a vanishing sediment discharge, whereas the entire Kosi River transports about $43 \mathrm{Mt}$ of suspended sediments every year (Sinha, 2009). However, the threshold theory reasonably predicts the trends of the thread morphology as the discharge increases (grey line in Fig. 7), which is obtained by fitting
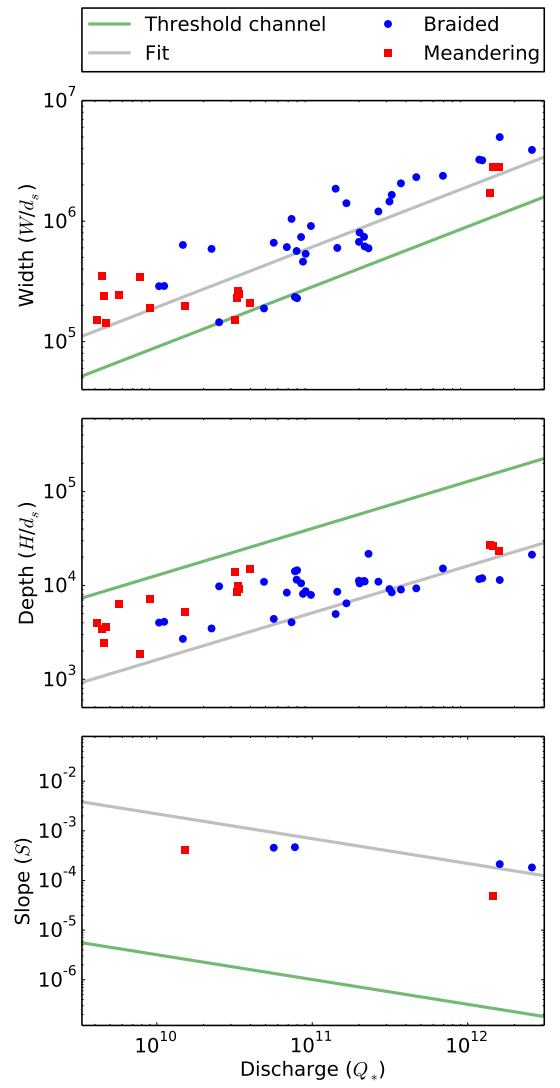

Figure 7. Width, depth and slope as functions of the water discharge. The solid green line corresponds to the threshold theory. The solid grey line is fitted to the data points.

the prefactors of the threshold relations (2), (3) and (4) to the data, while keeping their theoretical exponent. Furthermore the trends predicted by the threshold theory $\left(\beta_{w}=\beta_{h}=0.5\right.$ ) fall within the confidence intervals of empirical regressions for width but are slightly larger for depth.

\subsection{Detrending}

The semi-empirical regime relations based on the threshold theory represent analytically the dependency of the morphological parameters of a thread with respect to discharge. Therefore, we can use them to detrend our data with respect to discharge. To do so, we define the dimensionless width $W_{*}$, depth $H_{*}$ and slope $S_{*}$ as

$$
\begin{aligned}
& W_{*}=\frac{W}{d_{\mathrm{s}} \sqrt{Q_{*}}}=\frac{W\left(g d_{\mathrm{s}}\right)^{1 / 4}}{\sqrt{Q}}, \\
& H_{*}=\frac{H}{d_{\mathrm{s}} \sqrt{Q_{*}}}=\frac{H\left(g d_{\mathrm{s}}\right)^{1 / 4}}{\sqrt{Q}}, \\
& S_{*}=S \sqrt{Q_{*}}=\frac{S \sqrt{Q}}{g^{1 / 4} d_{\mathrm{s}}^{5 / 4}} .
\end{aligned}
$$



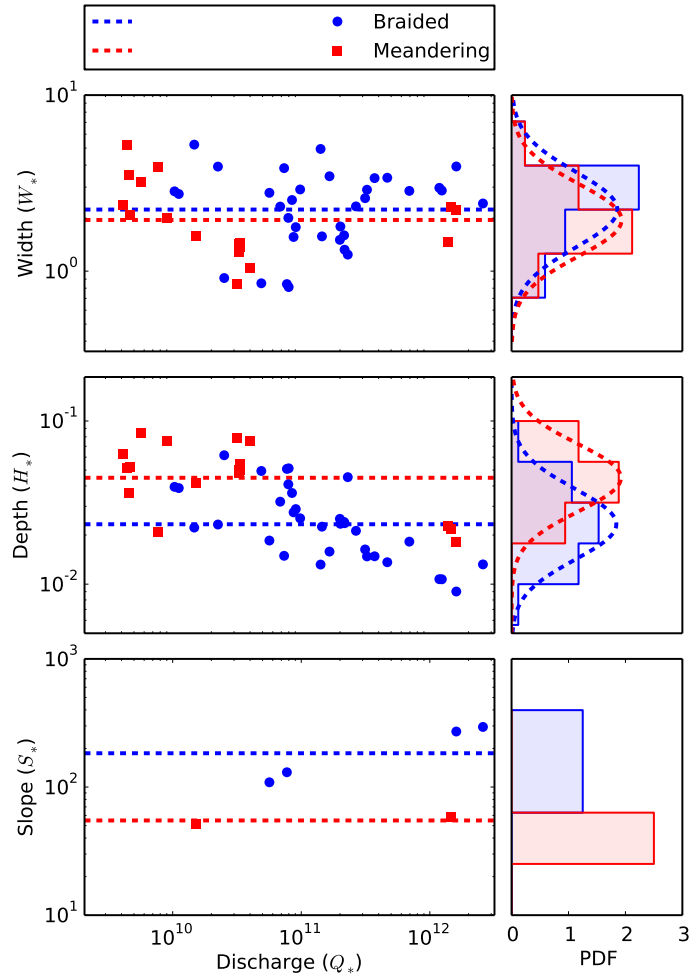

Figure 8. Left: dimensionless width $\left(W_{*}\right)$, depth $\left(H_{*}\right)$ and slope $\left(S_{*}\right)$ of the Kosi fan threads as functions of the dimensionless water discharge $\left(Q_{*}\right)$. Dashed blue and red lines indicate averages. Right: corresponding probability density functions.

As expected, both for meandering and braided threads, none of the dimensionless parameters above depend strongly on the water discharge (Fig. 8). OLS regression performed on $W_{*}$ confirms that it is entirely detrended at the $95 \%$ level of confidence. In contrast, depth $\left(H_{*}\right)$ is weakly correlated to discharge (slope of the regression is $-0.24 \pm 0.21$ and $R^{2}=0.2$ for the entire population). Further, the logarithms of the detrended width $\left(W_{*}\right)$ and depth $\left(H_{*}\right)$ are, by definition, the residuals of a linear correlation with the logarithm of discharge. These residuals should be normally distributed (Sokal and Rohlf, 1995; Scherrer, 1984). Normal tests confirm this at the $95 \%$ level of confidence (Fig. 8). OLS regression on the total population of slope measurements shows that there is no significant correlation between $S_{*}$ and $Q_{*}$ at the same level of confidence. Given the small number of slope measurements, this result should be regarded with wariness.

Finally, based on our data set, the threshold theory provides a first-order explanation for the observed trends.

\subsection{Braided vs. meandering threads}

Assuming that the dimensionless parameters $W_{*}, H_{*}$ and $S_{*}$ are independent from the water discharge, we may treat our data set as a sample from a statistically uniform ensemble.
As stated before, normal tests confirm this, at the $95 \%$ level of confidence (Fig. 8). Due to the large scatter in our data, these distribution are better expressed in terms of the common logarithm of the parameters.

For width, the mean value and standard deviation are $\left\langle\log _{10} W_{*}\right\rangle \approx 0.35$ and $\sigma\left(\log _{10} W_{*}\right) \approx 0.2$ for braided threads, and $\left\langle\log _{10} W_{*}\right\rangle \approx 0.29$ and $\sigma\left(\log _{10} W_{*}\right) \approx 0.2$ for meandering threads. An analysis of the variance shows that these distributions are equivalent for both mean and standard deviation. Using the same procedure, we find that the distributions of dimensionless depth have equal variances but different means: $\left\langle\log _{10} H_{*}\right\rangle \approx-1.63$ and $\sigma\left(\log _{10} H_{*}\right) \approx 0.2$ for braided threads, and $\left\langle\log _{10} H_{*}\right\rangle \approx-1.35$ and $\sigma\left(\log _{10} H_{*}\right) \approx$ 0.2 for meandering. Here, we cannot rule out the effect of the slight residual trend of the data.

Finally, the dimensionless slope of the braided threads is about 3 times higher than that of the meandering ones. Again our data set contains only four values for braided threads, and two values for meandering threads. Therefore, we cannot draw any statistically significant conclusion regarding the slope distribution.

Although clear trends emerge, the measurements from the Kosi River fan exhibit a large dispersion, which is clearly visualised by plotting the thread aspect ratio as a function of discharge (Fig. 6). As discussed before, this ratio is almost detrended. The analysis of the variance shows that both thread types have the same variance but different means. Braided threads tend to have a higher aspect ratio than meandering threads, in accordance with previous observations (Schumm, 1968; Eaton et al., 2010; Métivier and Barrier, 2012). However, this slight difference is overwhelmed by considerable scatter (from about 10 to 300). Our analysis suggest that this dispersion is not correlated with water discharge, indicating that other parameters, such as the sediment flux (Métivier and Barrier, 2012), vegetation (Tal and Paola, 2007) or bank cohesion (Schumm, 1960) influence the aspect ratio and possibly the depth of the threads of the Kosi fan. At this point, we need more data to strengthen the significance of our results.

\section{Conclusions}

In this paper, we have presented new observations from the Kosi megafan which allow for a comparison between the morphology of braided and meandering threads. Despite the limited extent of our data set, several first-order conclusions can be drawn.

The braided and meandering threads of the Kosi fan are morphologically comparable. Empirical regime equations relate their width and depth to flow discharge in the same way. Therefore, our knowledge about the hydraulic geometry of single-thread channels could be extended to braided threads. Because of this similarity, we can take advantage of the threshold channel theory to analyse field observations. 
The trend observed for the width of the threads is well predicted by this theory. This finding may be of interest for studies about hydraulic geometry of braided rivers, especially when concerned by their morphology. It can furthermore be used to evaluate thread discharge using satellite images (Ashmore and Sauks, 2006; Smith and Pavelsky, 2008; Passalacqua et al., 2013; Marra et al., 2014).

The simple scaling laws based on the threshold channel theory explain the detrending of the aspect ratio of both thread types. We find that the aspect ratio of both meandering and braided threads shows a large dispersion. This dispersion is practically uncorrelated with water discharge. We therefore suggest that the sediment flux, vegetation or bank cohesion are responsible for this dispersion (Métivier and Barrier, 2012). Because both vegetation and grain size seem to be homogeneous on the Kosi fan, we suspect that the sediment flux could be the main driver for the dispersion. The Kosi River fan would be an ideal field site to test these hypotheses, provided we can accurately measure the sediment discharge of its threads.

Finally, our first-order analysis calls for a more detailed comparative study of threads from braided and meandering rivers.

\section{The Supplement related to this article is available online at doi:10.5194/esurf-3-321-2015-supplement.}

Acknowledgements. This work was funded by the Indo-French Centre for Promotion of Advanced Research (CEFIPRA) through grant $4500-W 1$. We also thank the engineers and the staff of the Kosi River Project for their support in the field. We gratefully acknowledge J. Armitage for fruitful suggestions. This is IPGP contribution 3622 .

Edited by: D. Parsons

\section{References}

Ashmore, P.: Treatise on Geomorphology, vol. 9 of Fluvial Geomorphology, Academic Press, San Diego, CA, 289-312, 2013.

Ashmore, P. and Sauks, E.: Prediction of discharge from water surface width in a braided river with implications for at-a-station hydraulic geometry, Water Resour. Res., 42, 1-11, 2006.

Ashmore, P. E.: Laboratory modelling of gravel braided stream morphology, Earth Surf. Proc. Land., 7, 201-225, 1982

Bridge, J. S.: The interaction between channel geometry, water flow, sediment transport and deposition in braided rivers, Geol. Soc., London, Special Publications, 75, 13-71, 1993.

Bridge, J. S. and Gabel, S. L.: Flow and sediment dynamics in a low sinuosity, braided river: Calamus River, Nebraska Sandhills, Sedimentology, 39, 125-142, 1992.
Brownlie, W.: Compilation of alluvial channel data: laboratory and field, Tech. rep., W. M. Keck laboratory of hydraulics and water resources, California Institute of Technology, 209 pp., 1981a.

Brownlie, W.: Prediction of flow depth and sediment discharge in open channels, Tech. rep., W. M. Keck laboratory of hydraulics and water resources, California Institute of Technology, 232 pp., $1981 b$.

Chakraborty, T., Kar, R., Ghosh, P., and Basu, S.: Kosi megafan: historical records, geomorphology and the recent avulsion of the Kosi River, Quatern. Int., 227, 143-160, 2010.

Chauvet, H., Devauchelle, O., Métivier, F., Lajeunesse, E., and Limare, A.: Recirculation cells in a wide channel, Phys. Fluids (1994-present), 26, 016604, 1-10, 2014.

Church, M.: Proglacial fluvial and lacustrine environments, The Society of Economic Paleontologists and Mineralogists (SEPM), Glaciofluvial and Glaciolacustrine Sedimentation (SP23), 22100, 1975.

Church, M. and Rood, K.: Catalogue of Alluvial River Channel Regime Data, Univ. British Columbia, Department of Geography, Vancouver, 99 pp., 1983.

DeCelles, P. and Cavazza, W.: A comparison of fluvial megafans in the Cordilleran (Upper Cretaceous) and modern Himalayan foreland basin systems, Geol. Soc. Am. Bull., 111, 1315-1334, 1999.

Eaton, B., Millar, R. G., and Davidson, S.: Channel patterns: Braided, anabranching, and single-thread, Geomorphology, 120, 353-364, 2010.

Ferguson, R.: Understanding braiding processes in gravel-bed rivers: progress and unsolved problems, Geological Society, London, Special Publications, 75, 73-87, 1993.

Glover, R. and Florey, Q.: Stable channel profiles, Hydraulic laboratory report HYD no. 325, US Department of the Interior, Bureau of Reclamation, Design and Construction Division, 1951.

Gohain, K.: Morphology of the Kosi megafan,in: Alluvial Fans A Field Approach, edited by: Rachocki, A. H. and Church, M., Wiley, Chichester, 151-178, 1990.

Gole, C. V. and Chitale, S. V.: Inland delta building activity of Kosi river, in: Journal of the Hydraulics Division, Proceedings of the American Society of Civil Engineers, vol. 92, 111-126, 1966.

Hedman, E. R. and Osterkamp, W. R.: Streamflow characteristics related to channel geometry of streams in western United States, Geological Survey Water-Supply Paper, 2193, 1-17, 1982.

Henderson, F. M.: Stability of alluvial channels, T. Am. Soc. Civ. Eng., 128, 657-686, 1963.

Hundey, E. and Ashmore, P.: Length scale of braided river morphology, Water Resour. Res., 45, 1-9, 2009.

Lacey, G.: STABLE channels in alluvium (Includes Appendices), in: Minutes of the Proceedings, edited by: Telford, T., vol. 229, Proceedings of the Institution of Civil Engineers, Landoon, 259292, 1930.

Leopold, L. B., Wolman, M. G., Wolman, M. G., and Wolman, M. G.: River channel patterns: braided, meandering, and straight, US Government Printing Office Washington (DC), 39-85, 1957.

Mackin, J. H.: Concept of the graded river, Geol. Soc. Am. Bull., 59, 463-512, 1948.

Marra, W. A., Kleinhans, M. G., and Addink, E. A.: Network concepts to describe channel importance and change in multichannel systems: test results for the Jamuna River, Bangladesh, Earth Surf. Processes , 39, 766-778, 2014. 
Métivier, F. and Barrier, L.: Alluvial Landscape Evolution: What Do We Know About Metamorphosis of Gravel-Bed Meandering and Braided Streams?, Gravel-Bed Rivers: Processes, Tools, Environments, Wiley Online Library, 474-501, 2012.

Morlock, S. E.: Evaluation of acoustic Doppler current profiler measurements of river discharge, Water-Resources Investigations Report 95-4218, US Department of the Interior, US Geological Survey, Indianapolis, Indiana, 37 pp., 1996.

Mosley, M.: Response of braided rivers to changing discharge, J. Hydrol. New Zealand, 22, 18-67, 1983.

Osterkamp, W. R. and Hedman, E. R.: Perennial-streamflow characteristics related to channel geometry and sediment in Missouri River basin, USGS Professional Paper 1242, Washington, 37 pp., 1982.

Parker, G.: Self-formed straight rivers with equilibrium banks and mobile bed. Part 1. The sand-silt river, J. Fluid Mech., 89, 109125,1978

Parker, G.: Hydraulic geometry of active gravel rivers, J. Hydr. Eng. Div.-ASCE, 105, 1185-1201, 1979.

Parker, G., Wilcock, P. R., Paola, C., Dietrich, W. E., and Pitlick, J.: Physical basis for quasi-universal relations describing bankfull hydraulic geometry of single-thread gravel bed rivers, J. Geophys. Res.-Earth, 112, 1-21, 2007.

Parsons, D., Best, J., Orfeo, O., Hardy, R., Kostaschuk, R., and Lane, S.: Morphology and flow fields of three-dimensional dunes, Rio Paraná, Argentina: Results from simultaneous multibeam echo sounding and acoustic Doppler current profiling, J. Geophys. Res.-Earth, 110, 1-9, doi:10.1029/2004JF000231, 2005.

Passalacqua, P., Lanzoni, S., Paola, C., and Rinaldo, A.: Geomorphic signatures of deltaic processes and vegetation: The GangesBrahmaputra-Jamuna case study, J. Geophys. Res.-Earth , 118, 1838-1849, 2013.

Reitz, M., Jerolmack, D., Lajeunesse, E., Limare, A., Devauchelle, O., and Métivier, F.: Diffusive evolution of experimental braided rivers, Phys. Rev. E, 89, 052809, doi:10.1103/PhysRevE.89.052809, 2014.

Rennie, C. D. and Villard, P. V.: Site specificity of bed load measurement using an acoustic Doppler current profiler, J. Geophys. Res.-Earth, 109, F03003, 1-15, doi:10.1029/2003JF000106, 2004.

Richardson, W. R. and Thorne, C. R.: Multiple thread flow and channel bifurcation in a braided river: Brahmaputra-Jamuna River, Bangladesh, Geomorphology, 38, 185-196, 2001.

Sanders, L. L.: Manual of field hydrogeology, Prentice Hall, Upper Saddle River, NJ. 381 pp., 1998.

Scherrer, B.: Biostatistique, Chicoutimi, Québec: G. Morin, 816 pp., 1984.
Schumm, S.: The shape of alluvial channels in relation to sediment type, US Geol. Surv. Prof. Pap, 352-B, 17-30, 1960.

Schumm, S.: River adjustment to altered hydrologic regimen, Murrumbidgee River and paleochannels, Australia, US Govt. Print. Office, 65 pp., 1968.

Schumm, S.: The fluvial system, vol. 338, John Wiley and Sons, New York, 338 pp., 1977.

Seizilles, G.: Forme d'équilibre d'une rivière, $\mathrm{PhD}$ thesis, Paris 7, 179 pp., 2013.

Seizilles, G., Devauchelle, O., Lajeunesse, E., and Métivier, F.: Width of laminar laboratory rivers, Phys. Rev. E, 87, 052204, doi:10.1103/PhysRevE.87.052204, 2013.

Seni, S. J.: Sand-body geometry and depositional systems, Ogallala Formation, Texas, 36 pp., 1980.

Simpson, M. R.: Discharge measurements using a broad-band acoustic Doppler current profiler, US Department of the Interior, Open-File Report 01-1, US Geological Survey, USGS, Sacramento, California, 123 pp., 2001.

Singh, H., Parkash, B., and Gohain, K.: Facies analysis of the Kosi megafan deposits, Sediment. Geol., 85, 87-113, 1993.

Sinha, R.: The great avulsion of Kosi on 18 August 2008, Current Science, 97, 429-433, 2009.

Sinha, R., Gaurav, K., Chandra, S., and Tandon, S.: Exploring the channel connectivity structure of the August 2008 avulsion belt of the Kosi River, India: Application to flood risk assessment, Geology, 41, 1099-1102, 2013.

Smith, L. C. and Pavelsky, T. M.: Estimation of river discharge, propagation speed, and hydraulic geometry from space: Lena River, Siberia, Water Resour. Res., 44, 1-11, 2008.

Sokal, R. and Rohlf, F.: Biometry: the Principle and Practice of Statistics in Biological Research, 3rd edn., edited by: Freeman, W. H., New York, 850 pp., 1995.

Szupiany, R. N., Amsler, M. L., Best, J. L., and Parsons, D. R.: Comparison of fixed-and moving-vessel flow measurements with an $\mathrm{aDp}$ in a large river, J. Hydraul. Eng.-ASCE, 133, 1299-1309, 2007.

Tal, M. and Paola, C.: Dynamic single-thread channels maintained by the interaction of flow and vegetation, Geology, 35, 347-350, 2007.

Van den Berg, J. H.: Prediction of alluvial channel pattern of perennial rivers, Geomorphology, 12, 259-279, 1995.

Wells, N. A. and Dorr, J. A.: Shifting of the Kosi river, northern India, Geology, 15, 204-207, 1987.

Wilkerson, G. V. and Parker, G.: Physical basis for quasiuniversal relationships describing bankfull hydraulic geometry of sand-bed rivers, J. Hydraul. Eng.-ASCE, 137, 739-753, doi:10.1029/2006JF000549, 2010. 